The International Journal of Engineering and Science (IJES)

|| Volume || 6 || Issue || 6 || Pages || PP 64-68 || 2017 ||

ISSN (e): $2319-1813$ ISSN (p): $2319-1805$

THE IJES

\title{
Improving Material Removal Rate and Optimizing Variousmachining Parameters in EDM
}

\author{
*Vivek Kumar ** Prakash Kumar \\ *Research Scholar, Mechanical Engineering Department \\ **Assistant Professor, Production Engg. Department B.I.T. Sindri, Dhanbad
}

\begin{abstract}
-
Electric discharge machining is used as machining of electrically conductive hard material. In EDM lots of techniques are applied to improve material removal rate.In this project 'optimization of machining parameter' technique is used to improve the MRR in EDM process.There are large number of machining parameters involves in machining the work piece by using EDM process. In this project work an experiment is performed to investigate and optimize the effect of four machining parameters i,e, discharge current, pulse on time, pulse off time, and voltage which is based on Taguchi Design Method.For performing this experiment copper tool (electrode) is used with the 'mild steel' workpiece, and kerosene as dielctric fluid has been choosen.Experiment is performed with $L_{9}$ ORTHOGONAL ARRAY based on Taguchi design method. Signal-to-noise ratio is calculated to investigate the effect of input parameters more accurately. For analysis and explanation,graph is plotted between means of $S / N$ ratio for mrr and four machining parameters ( current. $T_{o n} T_{O F F}$, voltage) with the help of MINITAB 17 software.The model have been validated with analysis of variance (ANOVA).I found that discharge current has most significant factor,after that pulse on time, after that pulse off time and voltage has least significant effect.
\end{abstract}

Date of Submission: 02 June 2017

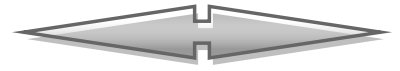

Date of Accepted: 24 June 2017

\section{INTRODUCTION}

Electric discharge machining is a non traditional manufacturing process based on removing material from a part by means of a series of repeated electrical discharge( created by electric pulse generators at short interval) between a tool,calledelectrode, and the part being machined in the presence of a dielectric fluid.In other words we can say in this procedure metal is removed from the work-piece due to erosion caused by rapidly formed spark discharge taking place between tool and work piece.This process is used to produce dies,punches and moulds,finishing parts for aerospace and automotive industry,and surgical components.

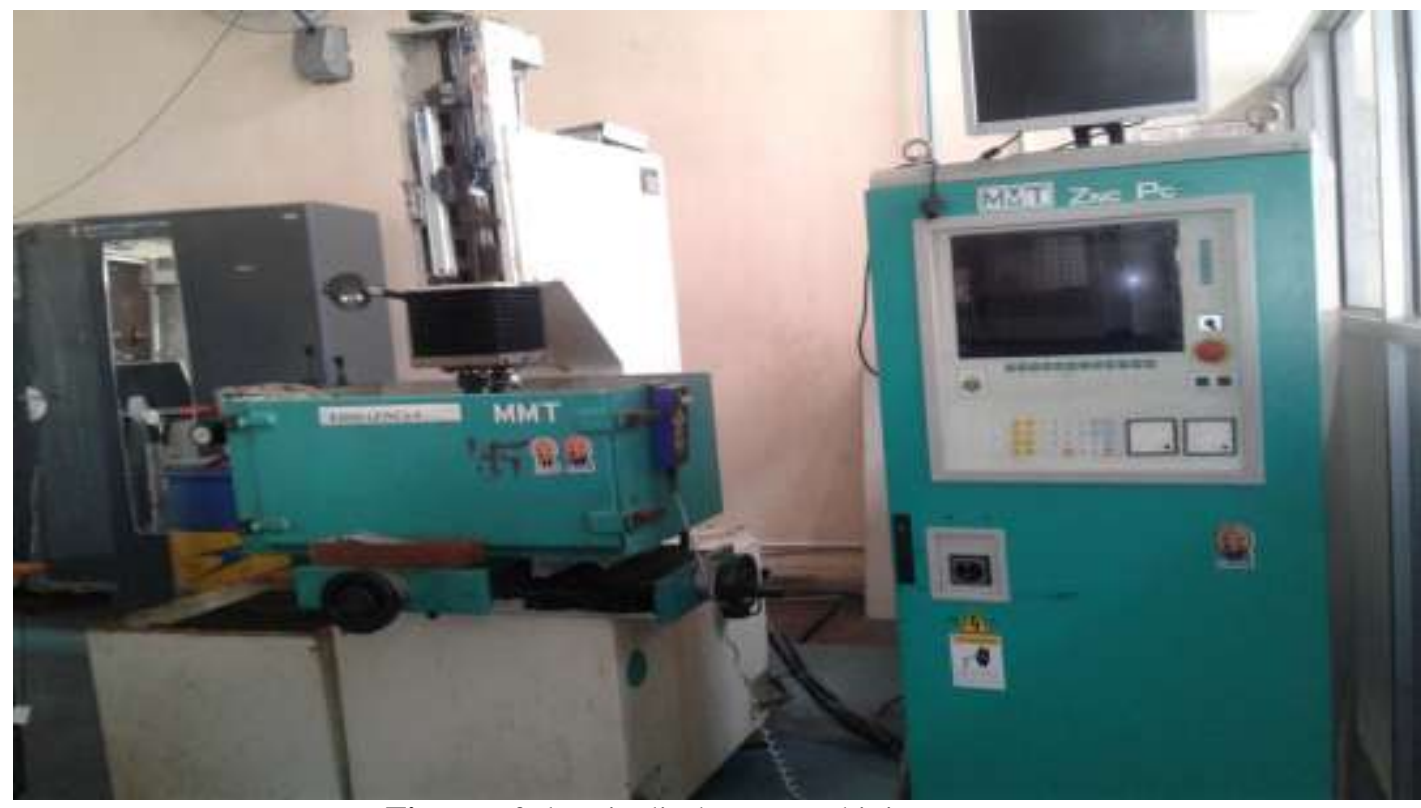

Figure of electric discharge machining process 


\section{LITERATURE REVIEW}

There is discussed below some research paper related to EDM.The studies carried out in these papers are mainly concerned with EDM parameter such as current,voltage,pulse on time,duty cycle etc and how these affect the material removal rate.

(a) B.S.Reddy carried out a study on the effect of EDM parameters over metal removal rate,tool wear rate, surface roughness and hardness.Mixed factorial design of experiments and multiple regression analysis techniques had been employed to achieve the desired results. The parameters in the decreasing order of importance for Mrr -duty cycle,current and voltage,Twr-current,servo duty cycle.

(b) M MRahman investigate the effect of peak current and pulse duration on performance characteristics of EDM.The conclusion drawn were,the current and pulse on time greatly affected the Mrr,Twr and SR.TheMrr increases almost linearly with increasing current for different pulse on time.

(c) Iqbal and khan concluded that the voltage and rotational speed of the electrode are the two significant parameters for EDM milling.Optimizing the EWR.

(d) T.Rajmohan experimented using design of experiment technique under L9 Orthogonal array design and considering the effect of machining parametrs of EDM such as pulse on time,pulse off time, current and voltage on mrr in machining of AISI304 stainless steel.For optimization they had been used signal to noise ratio and analysis of variance to analyze the effect of the parameters on mrr and also optimize the cutting parameters.

\section{PROBLEMSTATEMENT}

In EDM,the selection of parameters play a main role in producing good surface quality,highMrr and less electrode wear.This research aim is to investigate the proper selection of parameters in EDM for machining hundred material and studies these selected different parameters which are able to deliver better results in terms of material remoival rate and electrode wear of mild steel by copper electrode.Some machining parameters are such as pulse on time,pulse off time,arcgap,dischargecurrent,dutycycle,voltage etc.The problem might be interfere the result in this experiment when selection of parameters are not suitable and unproper to investigate on these machining characteristics

\section{OBJECTIVE OF PRESENT WORK}

The objective of this project work is to improve Mrr of mild steel work piece with copper tool by optimizing four machining parameters pulse on time,pulse off time,current and discharge voltage.

\section{SELECTION OF WORK PIECE}

In this experiment mild steel size $80 \times 60 \times 15 \mathrm{~mm} \times \mathrm{mm} \times \mathrm{mm}$ plate is chosen for conductive experiment.Mild steel has use in manufacturing industries.It offered in an extensive veriety of good products,practices and qualities than any other.It has excellent welding and forming characteristics, and it has very good corrosion resistance.

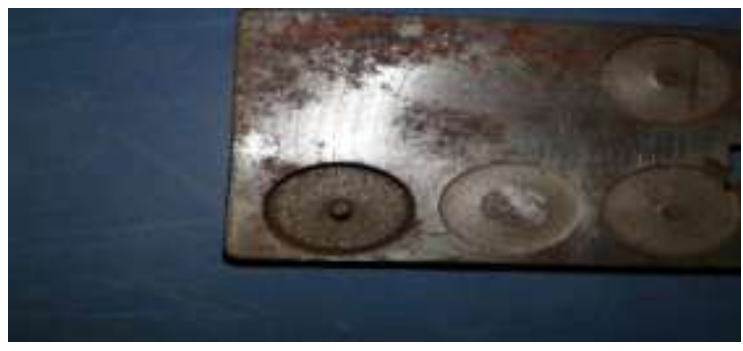

\section{SELECTION OF TOOL MATERIAL}

In this experiment copper tool rod of $8 \mathrm{~mm}$ dia and $60 \mathrm{~mm}$ length of cylindricalshape are taken.

\section{FORMULA OF MATERIAL REMOVAL CALCULATION}

MRR is calculated as proportion of change of weight of work piece before and after machining to the product of machining period and density of material.

M.R.R. $=\left(\mathrm{W}_{\mathrm{bm}}-\mathrm{W}_{\mathrm{am}}\right) \div(\mathrm{t} \times \dot{\rho})$

Where,

$\mathrm{W}_{\mathrm{bm}}=$ weight of work piece before machining

$\mathrm{W}_{\mathrm{am}}=$ weight of work piece after machining

$\mathrm{t}=$ machining period $=1$ minute

$\dot{\rho}=$ Density of mild steel work piece $=8000 \mathrm{~kg} / \mathrm{m}^{3}$ 


\section{TAGUCHI DESIGNMETHOD}

Dr. Genichi Taguchi of Nippon telephones \& telegraph company,japan has developed a method based on "ORTHOGONAL ARRAY" experiments which gives much reduced "variance" for the experiment with optimum settings of control parameters.

Hence,design of experiments with optimization of control parameters to obtain best result is achieved in Taguchi method.

Although various factors could be considered for controlling EDM process,but in the present project work,four process parameters namely discharge current, pulse-on-time,pulse-off time and average voltage are considered.

In this project work taguchi method is used to find out the optimal machining parameters for maximization of mrr in EDM process.

This method use the loss function to measure the performance parameters deviating from the desired value. The value of loss function is further transformed into a signal-to-noise $(\mathrm{S} / \mathrm{N})$ ratio.

There are mainly 3 types of performance parameters in the analysis of the $\mathrm{S} / \mathrm{N}$ ratio which is as follows:-

(a)Smaller-the-better

(b) Nominal-the-better

(c) Larger-the-better

The value of $\mathrm{S} / \mathrm{N}$ ratio for each level of process parameters is computed based on $\mathrm{S} / \mathrm{N}$ analysis. The characteristics of higher value represents better machining performance.For example material removal rate is termed as Larger-the-better.

Characteeristic of lower value represents better machining performance. For example surface roughness is termed as lower-is -better.

Hence it is concluded that for material removal rate "larger-is -better" were selected for finding optimum machining parameters.

VIII. MACHINING PARAMETERS AND THEIR LEVEL

\begin{tabular}{|l|l|l|l|c|c|}
\hline SYMBOL & $\begin{array}{l}\text { MACHINING } \\
\text { PARAMETERS }\end{array}$ & UNIT & & LEVELS & \\
\hline & & & LEVEL1 & LEVEL2 & LEVEL3 \\
\hline A & PEAK CURRENT & AMPERE & 4 & 6 & 8 \\
\hline B & PULSE ON TIME & SECOND & 40 & 80 & 120 \\
\hline C & PULSE OFF TIME & SECOND & 30 & 40 & 50 \\
\hline D & VOLTAGE & VOLT & 40 & 50 & 60 \\
\hline
\end{tabular}

\section{TAGUCHI ORTHOGONAL ARRAY EXPERIMENT}

MINITAB 17 Software is used for design of experiment in taguchi analysis.This software offers many possible ways in which an experiment can be carried out. A number of ordinary orthogonal arrays have been created to ease of experimental design.A number of ordinary orthogonal arrays have been created to ease of experimental design.A number of orthogonal arrays,such as $\mathrm{L}_{4}, \mathrm{~L}_{8}, \mathrm{~L}_{9}, \mathrm{~L}_{12}, \mathrm{~L}_{18}, \mathrm{~L}_{27}$ and so on created for two or three level factors.In this project, an $\mathrm{L}_{9}$ orthogonal array with four column and nine rows has has been used.This array had 10 degree of freedom and it uses 3-level design machining parameters.Here nine experiments are required to study the entire parameter space using $\mathrm{L}_{9}$ orthogonal array.In first column, peak current,second turn-on-time, $3^{\text {rd }}$ turn off time and $4^{\text {th }}$ column voltage has indicated.

\section{ANALYSIS OF SIGNAL TO NOISE (S/N) RATI0}

Since,There Are 3 Types Of Performance Characteristics I,E Smaller-The-Better,The -Larger-The Better.To Find Out Optimal Machining Performance,Greater-The-Bettercharacteristics for material removal rate has been taken for obtaining optimal machining performance.

The loss function (L) for objective of greater better is defined as follows:-

$\mathbf{L}_{\mathrm{G} . \mathrm{B}}=\mathbf{1} / \mathbf{n} \sum_{\mathrm{i}=1 \text { to n }} 1 / \mathbf{Y}_{\text {imrr }}^{2}$

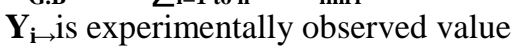

Where $Y_{\text {imrr }}$ denotes response for material removal rate

$\mathrm{n}$ denotes number of experiments.

The $\mathrm{S} / \mathrm{N}$ ratio response parameter can be calculated as a logarithmic of the loss function as shown below in

Taguchi $\mathrm{L}_{9}$ orthogonal array design.

S/N for MRR,

ท́ $=-10 \log _{10} 1 / \mathrm{n} \sum_{\mathrm{i}=1 \text { to n }} 1 / \mathrm{Y}_{\mathrm{imrr}}^{2}$ 
Improving Material Removal Rate And Optimizing Variousmachining Parameters In Edm

XI. EXPERIMENTAL DESIGN USING L 9 ORTHOGONAL ARRAY FOR COPPER ELECTRODES

\begin{tabular}{|l|l|l|l|l|l|l|l|l|}
\hline EXP.NO. & $\mathbf{I}_{\mathbf{P}}$ & $\mathbf{T}_{\text {on }}$ & $\mathbf{T}_{\text {off }}$ & $\mathbf{V}$ & wt.B.M. & wt.A.M. & MRR & S/N ratio \\
\hline $\mathbf{1}$ & 4 & 40 & 30 & 40 & 120.230 & 120.045 & 1.963 & 5.858 \\
\hline $\mathbf{2}$ & 4 & 80 & 40 & 50 & 120.045 & 119.755 & 3.078 & 9.765 \\
\hline $\mathbf{3}$ & 4 & 120 & 50 & 60 & 119.755 & 119.513 & 2.569 & 8.195 \\
\hline $\mathbf{4}$ & 6 & 40 & 50 & 50 & 119.513 & 119.141 & 3.949 & 11.929 \\
\hline $\mathbf{5}$ & 6 & 80 & 30 & 60 & 119.141 & 118.680 & 4.893 & 13.791 \\
\hline $\mathbf{6}$ & 6 & 120 & 40 & 40 & 118.680 & 118.262 & 4.437 & 12.941 \\
\hline $\mathbf{7}$ & 8 & 40 & 40 & 60 & 118.262 & 117.671 & 6.273 & 15.949 \\
\hline $\mathbf{8}$ & 8 & 80 & 50 & 40 & 117.671 & 116.951 & 7.643 & 17.665 \\
\hline $\mathbf{9}$ & 8 & 120 & 30 & 50 & 116.951 & 116.282 & 7.101 & 17.026 \\
\hline
\end{tabular}

\section{EFFECT OF INPUT FACTORS ON MRR}

With the help of MINITAB 17 software the plot between means of S/N ratio for mrr and discharge current has been plotted.Also plot between means of S/N ratio for mrr and pulse-on-time, plot between means of S/N rario for mrr and pulse-off-time, and plot between means of $\mathrm{S} / \mathrm{N}$ ratio for mrr and voltage has been plotted as shown in figure below:
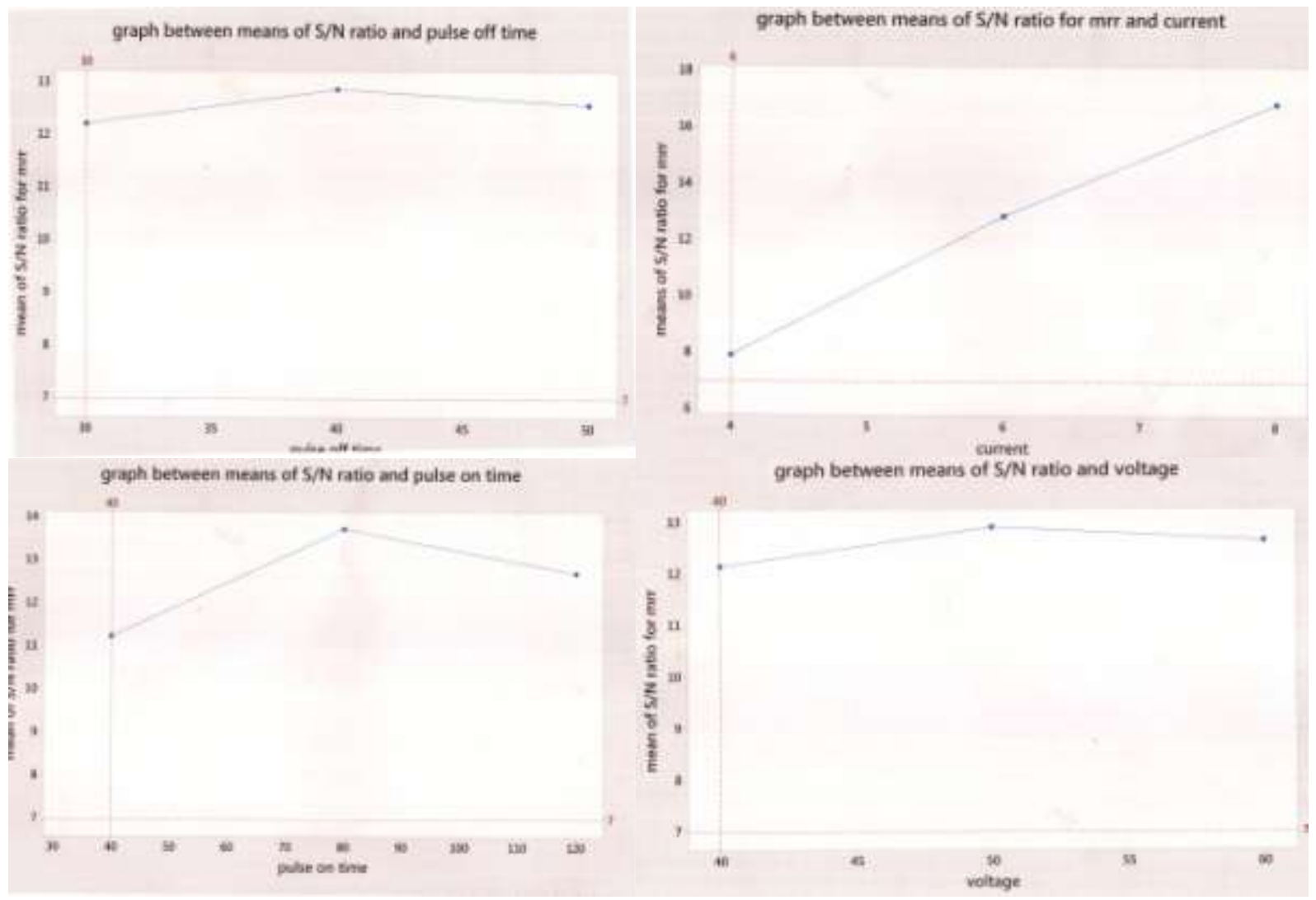

If line for a particular parameter is near horizontal,then the parameters has no significant effect.And if a parameter for which the line has the highest inclination will have the most significant effect.It is obvious from the four plots below, the parameter discharge current(I) has the most significant effect.From figure 2 , Turn-ontime has moderate significant effect and $\mathrm{T}_{\mathrm{OFF}}$ has least significant effect. Hence we can concluded that discharge current (I) is the most influencing parameter for the EDM process. According to taguchi design of experiment Greater-the-better quality characteristics for MRR of copper electrode,the optimum condition for each factor indicated is current 8 amp,pulse on time 80 second,pulse off time 50 second,voltage 40 volt.The optimal process parameter combination for maximum metal removing rate is found to be discharge current at highest level,pulse on time at second highest level,voltageat $3^{\text {rd }}$ highest level \& pulse off time at lowest level.Mean $\mathrm{S} / \mathrm{N}$ ratio for each level of parameters are called mean $\mathrm{S} / \mathrm{N}$ response table for MRR. Here cutting tool is made up of copper element,so the effect of machining parameter can be ranked as follows. 
TABLE-2- $\mathrm{s} / \mathrm{n}$ RATIO RESPONSE TABLE FOR MRR

\begin{tabular}{|l|l|l|l|l|}
\hline LEVEL & $\mathrm{I}_{\mathrm{P}}$ & $\mathbf{T}_{\text {on }}$ & $\mathrm{T}_{\text {off }}$ & $\mathrm{V}$ \\
\hline 1 & 7.939 & 11.245 & 12.225 & 12.154 \\
\hline 2 & 12.887 & 13.740 & 12.885 & 12.906 \\
\hline 3 & 16.88 & 12.720 & 12.596 & 12.645 \\
\hline DELTA & 8.941 & 3.515 & 0.949 & 1.013 \\
\hline RANK & 1 & 2 & 4 & 3 \\
\hline & & & & \\
\hline
\end{tabular}

With the help of responsetable ANOVA IS performed to find out which machining parameters significantly affect the output characteristics. Table 3- shows ANOVA results for MRR for copper electrode.This table shows $\%$ contribution of each parameter. For, MRR S/N ratio follows 'Greater-is -better' criteria. From the table below discharge current hasmaximum effect and Toff time has minimum effect and Ton has moderate effect on mrr of EDM Process parameters.

XII. .ANOVA RESULT FOR MRR USING CU ELECTRODE (TABLE 3)

\begin{tabular}{|l|c|c|c|c|}
\hline Sequence of variation & DOF & $\begin{array}{l}\text { Squential sum } \\
\text { of squares }\end{array}$ & $\begin{array}{l}\text { Mean } \\
\text { square(variance)M.S.=SF/DF }\end{array}$ & Contribution \\
\hline $\mathrm{I}_{\mathrm{P}}$ & 2 & 120.368 & 60.184 & $91.64 \%$ \\
\hline $\mathrm{T}_{\text {on }}$ & 2 & 9.441 & 4.7025 & $7.18 \%$ \\
\hline Toff & 2 & 0.656 & 0.328 & $0.49 \%$ \\
\hline Voltage & 2 & 0.874 & 0.437 & $0.66 \%$ \\
\hline Residual error & 2 & & & \\
\hline Total & 10 & 131.339 & & \\
\hline
\end{tabular}

\section{RESULT AND DISCUSSION}

From the Anova result for MRR using cu electrode as shown in table-3 below.It is clear that discharge current with a contribution of $91.64 \%$ has the greatest effect on performance characteristics (output characteristics).

Next parameter turn on time with a contribution of $7.18 \%$ has the next greatest effect on performance characteristics, after that voltage whose contribution is $0.66 \%$ and the last parameter Toff time has contribution $0.49 \%$ has least effect on performance characteristics.

\section{CONCLUSION}

In this investigation experiment on electric discharge machining to know the effect of machining outputs taken for consideration is material removal rate of the mild steel work piece using copper electrode tool by taguchi design method and improvement of mrr has been investigated.The experiment depends on various parameters for example discharge current, pulse-on-time (Ton), pulse-off-time and voltage has been selected.This experiment is based on $\mathrm{L}_{9}$ orthogonal array by taguchi design is conducted and minitab 17 software is used for this experiment. The main conclusion of this research are as follows:-

(a) Material removal rate of electric discharge machining can be improved by using optimization of various factors (discharge current,Ton,Toff,voltage) as determined within this work.

(b) Discharge current has most significant parameters for mrr.

(c) Voltage,\& Ton time is moderately effect the material removal rate.

(d) Toff has the least significant influence on MRR.

(e) The optimal process parameters that have been seen aboveobservationtable, the best contribution of process variables are current 8 ampere,Ton 80 second,voltage 40 volt.,Toff 50 second, for copper electrode

\section{REFERENCES}

[1] Sameh S. Habib (april 2014), Mechanical engg. Department,shoubra faculty of engineering,Benha university, cairo,Egypt done research on parameter optimization of EDM process by using taguchi approach.

[2] Dewangams.k. , Experimental investigation of machining parameters for EDM using U-shaped electrode of AISI P20 tool steel, mtech thesis (2010).

[3] Reddy sidda B. RAO PS, kumar JS and Reddy KVK, parametric study of electric discharge machining of AISI 304 stainless steel,IJEST.

[4] R.Soneys,F. Staelens, and W.Dekeyser, "Current trends in non conventional material removal process," Ann. CIRP, vol.35(2 ), p.467-480,1986.

[5] S.H. Tomadi, M.A. Hassan,2009,"Analysis of influence of EDM parameters on surface Quality,Material removal rate and Electrode wear of Tungsten carbide", proceeding of the International Multi Confrence of Engineers and computer scientist vol.-2,march, 1820

[6] Kuldeepojha,R.K. Garg, K.K. Singh 2010, “MRR Improvement in sinking EDM : A Review”,Journal of minerals and materials characterization and Engineering,vol.-9,no-8,pp.-709-739.

[7] Iqbal AKM. A. \&Khan A.A.,Optimization of process parameters on EDM milling of stainless steel AISI 304,Advanced Materials Research,264-265 (2011):p.p-979-984.

[8] VenkataRao.R,Advanced modeling and Optimization of manufacturing process,springer.2011.

[9] Kumar S, Singh R,Singh T.P. \&Sethi B.L., Surface modification by EDM:A review,Journal of materials processing technology 209 ( 8 (2009) p.p-3675-3687.

[10] Dhanabalan.S,SivakumarK,"Optimization of EDM parameters with multiple performance characteristics for Titanium grades". European Journal of scientific Research, vol 68,pp 297-305,2011. 